\title{
Aporte de serapilheira em plantios de eucalipto em função da qualidade do sítio
}

\author{
Thaís de Andrade Corrêa Neto ${ }^{1}$, Lúcia Helena Cunha dos Anjos ${ }^{1}$, Marcos Gervasio Pereira ${ }^{1}$, Carlos Fellipe de Siqueira Jaccoud ${ }^{2}$ \\ ${ }_{1}^{1}$ Universidade Federal Rural do Rio de Janeiro, Instituto de Agronomia, Departamento de Solos, Rod. BR 465 km 7, CEP 23.890-000, Seropédica, RJ, Brasil \\ ${ }^{2}$ Instituto Estadual do Meio Ambiente do Rio de Janeiro - INEA, Rua Bernardo Vasconcelos, n 154, CEP 28.970-000, Araruama, RJ, Brasil
}

\author{
"Autor correspondente: \\ tacneto@gmail.com.br \\ Termos para indexação: \\ Produção de serapilheira \\ Ciclagem de nutrientes \\ Matéria orgânica \\ Index terms: \\ Litter production \\ Nutrient cycling \\ Organic matter
}

\begin{abstract}
Resumo - Este estudo teve por objetivo avaliar a deposição e decomposição de serapilheira e o aporte de nutrientes em uma área de plantio de eucalipto em topossequência. Foi verificada contribuição significativa do estrato folhas, o que pode ser atribuído à idade do plantio. Em relação à velocidade de decomposição observa-se um decréscimo desta na estação da primavera em todos os sítios, sendo observadas diferenças entre os sítios relacionadas à topo-sequência. Verificou-se maior adição de $\mathrm{P}$ em relação ao $\mathrm{N}$ e K, existindo uma tendência dos maiores valores de $\mathrm{P}$ ocorrerem no terço superior da encosta. Os parâmetros estudados refletem as diferentes características dos sítios e suas limitações e sugerem dinâmicas de manejo diferenciadas.
\end{abstract}

\section{Litter production of eucalypt plantations according to site quality}

Historico do artigo:

Recebido em 03/6/2013

Aprovado em 28/11/2014

Publicado em 31/12/2014

doi: 10.4336/2014.pfb.34.80.484

\begin{abstract}
This study aimed to evaluate deposition and decomposition of litter and nutrient input in an area of eucalyptus plantation in top-sequence. It was verified significant contribution of the stratum leaves, what could be attributed to the age of the plantation. Regarding the rate of decomposition it was observed a decrease in the spring season at all sites. It was observed differences among sites related to top-sequence There was addition of nutrients as $\mathrm{P}, \mathrm{N}$ and $\mathrm{K}$, with a tendency for larger values of $\mathrm{P}$ in the top of the slope. The studied parameters reflect the different characteristics of the studied environmental growth conditions and their growth limitation and it suggest differences in the management of the areas.
\end{abstract}

\section{Introdução}

Estrategicamente o Brasil tem utilizado nos programas de reflorestamento as espécies de eucalipto como principal alternativa e, quase sempre, questiona-se sobre as mudanças que essas espécies podem promover no solo (Gama-Rodrigues et al., 2008). Pela extensão da área cultivada com eucalipto no País, há um crescente interesse em avaliar seus possíveis efeitos nos atributos do solo, visto que técnicas de manejo adequadas contribuem para melhor conservação dos solos e maior produtividade das espécies.

O desenvolvimento da floresta pode ser caracterizado pelas mudanças das características edáficas do solo, sendo elas a fauna (Chauvat et al., 2009), a comunidade microbiana e a eficiência da ciclagem de nutrientes (Trap et al., 2009, 2011). Parte do processo de retorno de matéria orgânica e da ciclagem nutrientes para o solo florestal se dá por meio da deposição da serapilheira, sendo essa considerada a via mais importante de 
transferência de elementos essenciais da vegetação para o solo.

Em relação à ciclagem de nutrientes e sua dinâmica nos diferentes pontos da paisagem, é importante ressaltar as diferenças edafoambientais de cada sítio, e como estas influenciam a dinâmica desse processo (Corrêa Neto et al., 2007). Gama-Rodrigues et al. (2005) observaram que o conhecimento da qualidade dos sítios implantados é essencial para se diagnosticar o potencial produtivo da cultura em uma determinada região, de modo a se constituir em uma alternativa rentável, principalmente em áreas ocupadas.

Em estudos realizados com eucaliptos consorciados, Tang et al. (2013) reforçam a importância da decomposição da serapilheira na fertilidade dos sítios, principalmente em áreas áridas mais rochosas, exemplificando como o compartimento composto pelas folhas é o que melhor reflete o estado nutricional das árvores. Devido a esse fato, pode-se observar facilmente o processo de retranslocação em folhas, principalmente nas grandes concentrações de nitrogênio e fósforo. No caso de Eucalyptus sp., é observado que $70 \%$ a $80 \%$ do fósforo pode ser translocado antes da queda das folhas. Bellote \& Silva (2000) ressaltam que o conhecimento do conteúdo de nutrientes na copa pode explicar o rápido crescimento do eucalipto em situações pós-estresse.

A quantidade de nutrientes absorvidos depende da exigência da espécie, da taxa de crescimento e das condições climáticas e edáficas que influenciam a disponibilidade do nutriente para as plantas. A exigência nutricional de uma espécie em comparação com outra pode variar de nutriente para nutriente, o que representa uma característica importante na seleção de sítios para o plantio e na determinação da qualidade e parcelamento de adubação. Os fatores que levam uma espécie a absorver maior ou menor quantidade de nutrientes mostram, em geral, interações complexas. De uma maneira mais simples, pode-se dizer que a exigência de uma espécie é relacionada à quantidade de nutrientes absorvida por unidade de biomassa reduzida, que corresponde à biomassa referente ao aporte de serapilheira. Portanto, a espécie que absorve maior quantidade de nutrientes por unidade de biomassa reduzida é mais exigente em comparação à outra que absorve menor quantidade.

As folhas atuam como principal compartimento na ciclagem de nutrientes. As variações dos teores foliares apresentam favoráveis indicadores de respostas metabólicas da planta em relação ao sítio submetido
(Novriyanti et al., 2012). Entretanto deve-se atentar para a idade dos povoamentos. Concentrações de $\mathrm{N} \mathrm{e}$ P observadas por Silva et al. (2011), nas folhas jovens completamente expandidas, apresentam pouca diferença no segundo e terceiro ano após o plantio e poderiam explicar as baixas diferenças em retranslocação para estes elementos.

No processo de ciclagem, o retorno de nutrientes por meio da queda de folhas e outras estruturas das árvores constituem a via mais importante do ciclo biogeoquímico. A produção e qualidade da serapilheira podem servir de indicadores para diferenças apresentadas entre plantios da mesma espécie ao longo de uma topo-sequência, e estão relacionados a vários fatores como às condições climáticas (Hattenschwiler et al., 2005 e Zhang et al., 2008).

Tendo em vista a relevância da utilização do eucalipto, torna-se importante o estudo do comportamento dessas espécies em diferentes tipos de solos. Dessa maneira pode-se futuramente, em colaboração com outros estudos, relacionar diferentes manejos para um mesmo talhão de eucalipto, sendo ele localizado sobre diferentes tipos de solos.

A partir do exposto o presente estudo teve como objetivo avaliar o aporte de serapilheira e adição de nutrientes em um talhão de plantio de Eucalyptus urophylla S.T. Blake, ao longo de uma topo-sequência, no qual apresenta três diferentes tipos de solos, localizado em Seropédica, RJ, utilizado para produção de matéria-prima para carvão.

\section{Material e métodos}

A área experimental situa-se no campus da Universidade Federal Rural do Rio de Janeiro (UFRRJ), em terras utilizadas pela empresa Saint Gobain Canalização, para plantio de Eucalyptus urophylla S.T. Blake (Sein \& Mitlöhner, 2011), com objetivo de produção de matéria-prima para carvão.

Os sítios de estudo foram selecionados em posições topográficas distintas de uma topo-sequência: terço superior (TS), terço médio (TM) e terço inferior (TI). Os solos foram diferenciados quanto à classe, características do terreno, influência do lençol freático e produtividade. No (TS) localiza-se um Argissolo Vermelho-Amarelo, no (TM) o Argissolo Amarelo, e no (TI) um Planossolo Háplico. Os plantios de eucalipto selecionados foram implantados na mesma época. 
O talhão onde foi instalado o plantio faz parte do Projeto Pró-Floresta III, implantado pela empresa Saint Gobain Canalização no período de dezembro de 2001 a janeiro de 2002. O experimento foi conduzido durante o ano de 2003. Cada área experimental possui 250 covas e o espaçamento de plantio utilizado foi o de $5 \mathrm{~m}$ x $2 \mathrm{~m}$. As seguintes práticas culturais foram realizadas pela empresa no talhão onde estão localizados os sítios do experimento: como operações de implantação destacam-se o combate às formigas, aplicação de glifosato, subsolagem e adubação de pré-plantio com $240 \mathrm{~kg} \mathrm{ha}^{-1}$ do formulado NPK (5-30-15). Como operações de manutenção, realizadas em 2002, foram realizadas, gradagem e roçada mecânica nas áreas planas, roçada manual nas áreas de relevo ondulado, combate às formigas e adubação de cobertura com $100 \mathrm{~kg} \mathrm{ha}^{-1}$ do formulado NPK (20-00-20).

Para a coleta do material decíduo depositado, foram instalados 10 coletores cônicos em cada sítio selecionado. Para sua construção foi utilizado um círculo construído com um tubo de 3/4 polegadas, de material plástico de polietileno, formando uma área de circunferência correspondente a $0,1864 \mathrm{~m}^{2}$, disposto em forma circular com duas extremidades emendadas com cordões nas árvores. Esse círculo, no formato de "bambolê", foi acoplado a um coletor cônico, para retenção do material aportado, feito com malha de polietileno tipo sombrite agrícola.

Posteriormente a cada coleta, após secagem ao ar, o material foi estratificado em: folhas, ramos, material reprodutivo e outros (frações não identificáveis). Após essa etapa, o material decíduo foi seco à temperatura de $65{ }^{\circ} \mathrm{C}$ por 48 horas, sendo posteriormente pesado a fim de avaliar a contribuição de cada fração no aporte total do material decíduo. O aporte total em cada sítio para cada estação foi determinado a partir da média harmônica dos dez coletores.

A quantidade de material decíduo produzido anualmente, para cada área de estudo, foi estimada a partir seguinte expressão, modificada de Lopes et al. (2002):

$\mathrm{PMD}=(\Sigma$ PMMD $\times 10.000) / \mathrm{Ac}$

Em que: $\mathrm{PS}=$ Produção de material decíduo $\left(\mathrm{kg} \mathrm{ha}^{-1}\right.$ ano $\left.^{-1}\right) ;$ PMDM = Produção mensal de material decíduo $\left(\mathrm{kg} \mathrm{mês}{ }^{-1}\right)$, obtida pela média dos 10 coletores; $\mathrm{Ac}=$ Área do coletor $\left(\mathrm{m}^{2}\right)$. Posteriormente PMD foi convertida para $\mathrm{Mg} \mathrm{ha}^{-1} \mathrm{ano}^{-1}$.
Após triagem e quantificação da contribuição de cada fração no aporte total, as amostras foram transferidas para bandejas e homogeneizadas. As amostras, obtidas mensalmente para cada área, foram unidas duas a duas, totalizando cinco amostras para cada mês, perfazendo cinco repetições. Esse material foi moído e submetido à digestão sulfúrica (Tedesco et al., 1995). No extrato obtido foram determinados os teores dos nutrientes: $\mathrm{N}$, $\mathrm{P}$ e K. O conteúdo dos nutrientes foi determinado pela multiplicação dos teores $\left(\mathrm{g} \mathrm{kg}^{-1}\right)$ pela massa do material aportado $\left(\mathrm{Mg} \mathrm{ha}^{-1}\right)$, sendo convertidos no final para $\mathrm{kg}$ ha $^{-1}$, e calculada a média harmônica de três repetições de laboratório. As coletas foram feitas na estação do verão, outono e inverno do ano de 2003.

A taxa de decomposição da serapilheira foi quantificada através do valor " $k$ " da equação proposta por (Olson, 1963), $\mathrm{k}=\mathrm{L} / \mathrm{X}$, onde $\mathrm{k}=$ taxa de decomposição da serapilheira, $\mathrm{L}=$ produção estacional de material decíduo e $\mathrm{X}=$ produção de serapilheira acumulada.

Através desse método foi possível avaliar a medida da perda de massa para cada sítio. O valor " $k$ " consiste em uma relação entre material orgânico depositado em um período de tempo conhecido e o material acumulado por um tempo indeterminado. Quanto maior for o valor " $k$ " maior será a velocidade de decomposição. As coletas de material para o cálculo do valor " $k$ " foram realizadas através de um coletor construído com um arco de circunferência com área de $0,1864 \mathrm{~m}^{2}$, igual ao do coletor cônico, no final de cada estação. O arremesso do arco foi feito logo abaixo do local onde foi instalado o coletor cônico. Foram calculadas três repetições de campo e a média harmônica pelo programa SISVAR 5.3 (Ferreira, 2010).

Os dados obtidos em campo para as análises de material decíduo e taxa de decomposição foram submetidos à análise estatística ANOVA e teste t (LSD) com 5\% de probabilidade, pelo programa SISVAR 5.3 (Ferreira, 2010). Os teores de NPK obtidos foram submetidos à análise estatística ANOVA e teste Tuckey com 5\% de probabilidade, pelo programa SISVAR 5.3 (Ferreira, 2010). Os dados referentes às médias da deposição do material decíduo e às médias da taxa de decomposição ( "valor k"), por apresentarem o coeficiente de variação elevado, foram submetidos à transformação dos dados pela raiz quadrada de $\mathrm{Y}=1,0-\mathrm{SQRT}(\mathrm{Y}+1,0)$. SISVAR 5.3 (Ferreira, 2010). 


\section{Resultados e discussão}

Os perfis selecionados foram classificados pelo $\mathrm{SiBCS}$ até o segundo nível categórico em, Planossolo Háplico, Argissolo Amarelo e Argissolo Vermelho Amarelo, localizados respectivamente no terço inferior, médio e superior, conforme descrição apresentada na Tabela 1.

Quanto ao material decíduo depositado, foi verificada maior contribuição do estrato folhas para o sistema. Os outros estratos não apresentaram valores relevantes. Portanto, o material decíduo quantificado nesse experimento será expresso pela produção de folhas. Esse padrão pode ser atribuído à baixa maturidade do plantio, já que não foram estabelecidas algumas funções vegetativas, não fazendo parte da ciclagem alguns estratos como flores, sementes entre outros. Pode-se observar o mesmo nos estudos realizados por Corrêa et al. (2013), onde encontraram predominância do estrato folhas em aporte de Eucalyptus dunnii Maiden na idade de 1 a 2 anos.

No verão os valores de deposição de material decíduo foram sempre menores, quando comparados aos de outono, exceto para o sítio localizado no terço inferior (TI), que apresentou padrão inverso (Tabela 2).

O sítio (TI), onde se localiza o Planossolo, apresenta menor permeabilidade e impedimento de drenagem, a umidade permanece mais tempo no sistema diminuindo a abscisão de folhas, fato refletido na estação seguinte. Nos sistemas de drenagem mais eficientes, o conteúdo de água é rapidamente drenado para o lençol freático, criando mecanismos para a vegetação se adaptar a condições de maior estresse hídrico, sendo a abscisão favorecida e consequentemente maior quantidade de material decíduo é produzida.

A deposição de folhas apresenta-se de forma bastante semelhante para os terços, superior e médio (TS e TM) da topo-sequência, acompanhando o mesmo comportamento de máximos e mínimos em relação as quatro estações do ano. Já no TI, observa-se padrão inverso quando comparado aos terços superior e médio (Tabela 2). Os maiores e menores valores de deposição de folhas ocorrem no TI. Sendo os maiores no verão e inverno, e os menores no outono e primavera. Esse comportamento pode indicar a influência hídrica nesse sítio, conforme também demonstrado em estudos de Lu \& Liu (2012), onde florestas de diferentes altitudes em Taiwan apresentam correlação positiva na queda de folhas conforme a variação de temperatura e umidade.
Ao comparar a produção de material decíduo (folhas) (PMD) entre os sítios, verifica-se que no verão e inverno a produção de material segue padrões semelhantes, assim como no outono e na primavera, ressaltando entre eles o padrão inverso dos terços superior e médio em relação ao terço inferior. Para os primeiros, a PMD no outono apresenta valores superiores quando comparado a outras estações. Já no TI o padrão apresenta-se inverso, ou seja, a PMD no outono apresenta menores valores e no verão a quantidade de material depositado aumenta.

A partir dos dados obtidos na coleta do material decíduo, foi calculada a constante de decomposição valor " $k$ ". Comparando-se esse valor dentro dos diferentes sítios durante as estações, foi observado um decréscimo na estação da primavera em todos os sítios. Já no inverno ocorre um aumento significativo na área do TI (Tabela 3). Dentro das estações do ano não existem diferenças significativas entre os sítios estudados, exceto para o TI no inverno o qual aumenta consideravelmente.

Esse padrão no terço inferior pode estar relacionado à menor permeabilidade da água no Planossolo, resultando em maior teor de umidade no solo, diferentemente das outras áreas, o que influencia na velocidade de decomposição do material decíduo. No TS e TM na estação do inverno, onde ocorre o déficit hídrico, a constante é menor, devido a pouca ocorrência de abscisão de folhas.

Estudando a velocidade de decomposição da serapilheira em plantios de Eucalyptus grandis, Cunha et al. (2005) verificaram diferenças na constante "valor $k$ " em função da idade do talhão, sendo observados valores de 0,$93 ; 0,67$ e 0,35 para o talhão de primeira rotação e para as rebrotas de 1,5 e 5 anos. O autor sugere que a estimativa do "valor $k$ " deve ser interpretada com certas limitações, em razão de a taxa de adição de material não ser constante.

Apesar das áreas apresentarem valores de decomposição diferentes entre si, elas mostram a mesma tendência de oferta de material decíduo, o que é decorrente dos plantios nas três áreas terem sido feitos na mesma época, com a mesma espécie e mesmo manejo. Os diferentes valores de " $k$ ", por outro lado, expressam as diferenças dos solos em cada sítio, no que se refere principalmente a umidade e disponibilidade de água.

Resultados de teores de nutrientes no material vegetal, demonstram ocorrer no TS maiores $(0,83 \%)$ e menores $(0,54 \%)$ teores de nitrogênio nas folhas no verão e no inverno respectivamente (Tabela 4), sendo explicado pela 
influência das precipitações e do tipo de solo que ocorrem nos diferentes sítios da topo-sequência. No verão, o menor teor de nitrogênio encontrado no TI está relacionado à baixa taxa de decomposição das folhas conjugado à textura mais arenosa do Planossolo, sendo o verão a estação de precipitações torrenciais, o que favorece a lixiviação do nitrogênio para a posição mais inferior da topo-sequência, como o gleissolo. Barros \& Novais (1990) afirmam em seus estudos que a absorção do nitrogênio é influenciada pela disponibilidade de água no sistema. Dessa forma, é observado na posição mais elevada da topo-sequência um padrão diferencial em relação ao TM e TI.

Tabela 1. Descrição dos perfis localizados ao longo da topossequência estudada.

\begin{tabular}{|c|c|c|c|}
\hline & Perfil: Planossolo Háplico (TI) & Perfil: Argilssolo Amarelo (TM) & Argissolo Vermelho Amarelo (TS) \\
\hline Situação de declive & $\begin{array}{l}\text { Descrito e coletado em trincheira, } \\
\text { no terço inferior da elevação }\end{array}$ & $\begin{array}{l}\text { Descrito e coletado em trincheira, } \\
\text { no terço médio da elevação }\end{array}$ & $\begin{array}{l}\text { Descrito e coletado em trincheira, } \\
\text { no terço superior da elevação }\end{array}$ \\
\hline Litologia & Sedimentos aluviais e coluviais & Terciário/Quaternário & $\begin{array}{l}\text { Rochas gnáissicas do Pré- } \\
\text { Cambriano CD }\end{array}$ \\
\hline Material de origem & $\begin{array}{l}\text { Produto de alteração do material } \\
\text { supracitado }\end{array}$ & $\begin{array}{l}\text { Sedimentos coluviais argilosos do } \\
\text { Terciário/Quaternário }\end{array}$ & Saprolito dos materiais supracitado \\
\hline Pedregosidade & Não pedregoso & Não pedregoso & Não pedregoso \\
\hline Rochosidade & Não rochoso & Não rochoso & Não rochoso \\
\hline Relevo local & Plano e suave ondulado & Plano e suave ondulado & Plano e suave ondulado \\
\hline Relevo regional & Plano e suave ondulado & $\begin{array}{l}\text { Plano e ondulado de topo } \\
\text { arredondado }\end{array}$ & $\begin{array}{l}\text { Plano e ondulado de topo } \\
\text { arredondado }\end{array}$ \\
\hline Erosão & Laminar não aparente & Laminar ligeira & Laminar ligeira \\
\hline Drenagem & Imperfeitamente drenado & Moderadamente drenado & Bem drenado \\
\hline Vegetação primária & Floresta tropical subcaducifolia & & Floresta tropical subcaducifolia \\
\hline Vegetação atual & Eucalipto & Eucalipto & Eucalipto \\
\hline Clima: ( Köppen) & Aw, segundo & Aw, segundo & Aw, segundo \\
\hline
\end{tabular}

Tabela 2. Médias harmônicas da deposição do material decíduo "folhas" (Mg ha"-1) nos terços: superior (TS), médio (TM) e inferior (TI) nas estações do ano.

\begin{tabular}{lrccc}
\hline \multirow{2}{*}{ Terço } & \multicolumn{4}{c}{ Estações do ano } \\
\cline { 2 - 5 } & Verão & Outono & Inverno & Primavera \\
\hline TS & $9,56 \mathrm{~b}$ & $12,74 \mathrm{ab}$ & $9,51 \mathrm{ab}$ & $12,78 \mathrm{a}$ \\
TM & $7,64 \mathrm{~b}$ & $12,93 \mathrm{a}$ & $7,44 \mathrm{~b}$ & $8,16 \mathrm{a}$ \\
TI & $20,07 \mathrm{a}$ & $6,21 \mathrm{~b}$ & $15,39 \mathrm{a}$ & $3,63 \mathrm{~b}$ \\
\hline
\end{tabular}

Valores diferentes seguidos de letras diferentes,nas colunas, são significativos pelo teste Tukey a $5 \%$ de probabilidade. CV=28,71\% após a transformação dos dados pela raiz quadrada de $\mathrm{Y}=1,0-\mathrm{SQRT}(\mathrm{Y}+1,0)$. Valores referentes a 4 estações do ano.

Tabela 3. Médias harmônicas para os valores da taxa de decomposição "valor k" nos terços: superior (TS), médio (TM) e inferior (TI) nas estações do ano.

\begin{tabular}{lcccc}
\hline \multirow{2}{*}{ Terço } & \multicolumn{4}{c}{ Estações do ano } \\
\cline { 2 - 5 } & Verão & Outono & Inverno & Primavera \\
\hline TS & 0,53 & 1,00 & $0,53 \mathrm{~b}$ & 0,34 \\
TM & 0,49 & 0,86 & $0,59 \mathrm{ab}$ & 0,35 \\
TI & 0,23 & 0,86 & $1,51 \mathrm{a}$ & 0,28 \\
\hline
\end{tabular}

Valores diferentes seguidos de letras diferentes,nas colunas, são significativos pelo teste Tukey a 5\% de probabilidade. CV=13,98\% após a transformação dos dados pela raiz quadrada de $\mathrm{Y}=1,0-\mathrm{SQRT}(\mathrm{Y}+1,0)$. Valores referentes a 4 estações do ano. 
Tabela 4. Médias harmônicas dos teores de nitrogênio (\%) na digestão do material decíduo "folhas" nos terços: superior (TS), médio (TM) e inferior (TI) nas estações do ano.

\begin{tabular}{llccc}
\hline \multirow{2}{*}{ Terço } & \multicolumn{4}{c}{ Estações do ano } \\
\cline { 2 - 5 } & Verão & Outono & Inverno & Primavera \\
\hline TS & $0,69 \mathrm{~b}$ & 1,00 & $0,53 \mathrm{~b}$ & 0,34 \\
TM & $0,76 \mathrm{ab}$ & 0,86 & $0,59 \mathrm{ab}$ & 0,35 \\
TI & $0,83 \mathrm{a}$ & 0,89 & $1,51 \mathrm{a}$ & 0,28 \\
\hline
\end{tabular}

Valores diferentes seguidos de letras diferentes, nas colunas, são significativos pelo teste Tukey a $5 \%$ de probabilidade. $\mathrm{CV}=8,10 \%$. Valores referentes a 4 estações do ano.

Para os teores de fósforo no material decíduo, o sítio TS (Tabela 5) apresenta teores mais elevados em todas as estações do ano. No TS, o fósforo apresenta-se mais adsorvido em função do maior teor de argila e teor de carbono orgânico verificado nas camadas superficiais (Corrêa Neto et al., 2007), contribuindo para uma maior absorção. Ribeiro et al. (2010) associam em seus estudos que a produção de matéria seca da parte aérea e de raízes no eucalipto, bem como a altura, foram influenciados pelo tipo e densidades dos solos, doses de fósforo, com interação entre os fatores.

Padrões inversos (Tabela 5) nos fluxos vitais de formação nos dois sítios TI e TS, são resultantes da intensidade de lixiviação, acúmulo de água e perda de matéria orgânica, isto é, todos os agentes pré-estabelecedores de um meio diferenciado para organismos que habitam o sistema em estudo. Ao comparar as estações do ano, no verão observam-se maiores teores de P no material vegetal, o que expressa a maior absorção deste elemento quando ocorre maior precipitação pluviométrica.

Ao analisar os teores de potássio (Tabela 6) no material decíduo, foi observado padrão diferenciado do encontrado na literatura. Barros \& Novais (1990) relatam que teores de potássio presentes na biomassa do eucalipto são mais elevados que os teores de fósforo, em plantios de três anos e meio a oito anos. Verificase que na Tabela 5 os teores de fósforo apresentam- se relativamente maiores quando comparados aos de potássio, principalmente nas estações de verão e outono. Provavelmente, isso ocorre devido à idade do eucalipto e à contribuição do material decíduo ser predominantemente do estrato folhas, o que não foi verificado nos estudos citados. Maiores teores de potássio ocorrem no inverno, o que também sugere diferenças na qualidade do material decíduo.

A movimentação do íon potássio no solo, em direção às raízes se dá predominantemente por difusão. Contudo, em solos arenosos e com baixa capacidade de troca de cátions (CTC) a movimentação por fluxo de massa pode assumir uma importância maior (Barros \& Novais, 1990). Nos solos tropicais utilizados para o plantio do eucalipto, a perda de potássio por lixiviação pode ser considerável, em razão da baixa CTC. O efeito da mobilidade do potássio e perda por lixiviação é observado ao se analisar a Tabela 6 , onde, no solo situado no TI, Planossolo de textura superficial arenosa, ocorrem os menores teores de potássio no material decíduo em todas as estações coletadas, refletindo os mesmos resultados no solo associado às maiores perdas por lixiviação.

A absorção de nitrogênio, fósforo e potássio em maior quantidade pode ser associada à maior produtividade $\mathrm{e}$ poderia ser usado como indicador de qualidade do sítio (Barros \& Novais, 1990; Santana et al., 2008).

Tabela 5. Médias harmônicas dos teores de fósforo (\%) na digestão do material decíduo "folhas" nos terços: superior (TS), médio (TM) e inferior (TI) nas estações do ano.

\begin{tabular}{lccc}
\hline \multirow{2}{*}{ Terço } & \multicolumn{3}{c}{ Estações do ano } \\
\cline { 2 - 4 } & Verão & Outono & Inverno \\
\hline TS & $0,10 \mathrm{c}$ & $0,06 \mathrm{c}$ & $0,09 \mathrm{c}$ \\
TM & $0,20 \mathrm{~b}$ & $0,08 \mathrm{~b}$ & $0,13 \mathrm{~b}$ \\
TI & $0,35 \mathrm{a}$ & $0,18 \mathrm{a}$ & $0,3 \mathrm{a}$ \\
\hline
\end{tabular}

Valores diferentes seguidos de letras diferentes, nas colunas, são significativos pelo teste Tukey a 5\% de probabilidade. CV=3,53\%. Valores referentes a 4 estações do ano. 
Tabela 6. Médias harmônicas dos teores de potássio (\%) na digestão do material decíduo "folhas" nos terços: superior (TS), médio (TM) e inferior (TI) nas estações do ano.

\begin{tabular}{lccc}
\hline \multirow{2}{*}{ Terço } & \multicolumn{3}{c}{ Estações do ano } \\
\cline { 2 - 4 } & Verão & Outono & Inverno \\
\hline TS & $0,01 \mathrm{c}$ & $0,05 \mathrm{c}$ & $0,04 \mathrm{c}$ \\
TM & $0,04 \mathrm{~b}$ & $0,04 \mathrm{~b}$ & $0,13 \mathrm{~b}$ \\
TI & $0,16 \mathrm{a}$ & $0,18 \mathrm{a}$ & $0,26 \mathrm{a}$ \\
\hline
\end{tabular}

Valores diferentes seguidos de letras diferentes, nas colunas, são significativos pelo teste Tukey a 5\% de probabilidade $\mathrm{CV}=13,97 \%$. Valores referentes a 4 estações do ano.

\section{Conclusões}

Os parâmetros avaliados: aporte de serapilheira, material decíduo, digestão foliar e taxa de decomposição, evidenciam as diferenças entre os sítios estudados e relaciona-os às suas diferentes características de drenagem. Ressaltam-se padrões fora da tendência para o sítio do terço inferior da encosta, sendo observadas baixas taxas de potássio e fósforo em relação aos demais. É importante inferir na interpretação dos resultados obtidos e análises dos parâmetros a ocorrência da limitação à idade dos plantios, conforme observado. Entretanto, os parâmetros estudados refletem as diferentes características dos sítios e suas limitações e sugerem dinâmicas de manejo diferenciadas, o que indica a adoção de distintas técnicas de plantio, como espaçamento, tipo de aplicação de nutrientes, dentre outros.

\section{Referências}

BARROS, N. F; NOVAIS, R. F. Relação solo-eucalipto. Viçosa, MG: Ed. da UFV 1990. 330 p.

BELlOTE, A. F. J.; SILVA, H. D. Técnicas de amostragens e avaliações nutricionais em plantios de Eucalyptus spp. In: GONCALVES, J. L. de M.; BENEDETTI, V. (Ed.). Nutrição e fertilização florestal. Piracicaba: IPEF, 2000. p. 105-133.

CHAUVAT, M.; ZAITSEV, A. S.; GABRIEL, E.; WOLTERS, V. How do soil fauna and soil microbiota respond to beech forest growth? Current Zoology, v. 55, p. 272-278, 2009.

CORRÊA NETO, T. A.; ANJOS, C. dos L. H.; PEREIRA, M. G. AMORIM, H. B. JACCOUD, C. F. S. Atributos edafoambientais e parâmetros dendométricosde plantios de eucaplipto em uma topossequencia no campus da UFRRJ - Seropédica (RJ). Ciência Florestal, Santa Maria, RS, v. 17, n. 1, p. 43-51, jan./mar., 2007.

CORRÊA, R. S.; SCHUMACHER, M. V.; MOMOLLI D. R. Deposição de serapilheira e macronutrientes em povoamento de Eucalyptus dunnii Maiden sobre pastagem natural degradada no Bioma Pampa. Scientia Forestalis, Piracicaba, v. 41, n. 97, p. 065-074, 2013.
CUNHA, G. M.; GAMA-RODRIGUES, A. C. G.; COSTA, G. S. Ciclagem de nutrientes em Eucalyptus grandis W. Hill ex Maiden no Norte Fluminense. Revista Árvore, Viçosa, MG, v. 29, n. 3, p. 353-363, 2005.

FERREIRA, D. F. Sisvar 5.3 (Build 77). Lavras: UFLA, 2010.

GAMA-RODRIGUES, E. F.; BARROS, N. F.; GAMA-RODRIGUES, A. C.; ARAÚJO, G. Nitrogênio, carbono e atividade da biomassa microbiana do solo em plantações de eucalipto. Revista Brasileira de Ciência do Solo, Viçosa, MG, v. 29, p. 898-901, 2005.

GAMA-RODRIGUES, E. F.; BARROS, N. F.; VIANA, A. P.; SANTOS, G. A. Alterações na biomassa e na atividade microbiana da serapilheira e do solo, em decorrência da substituição de cobertura florestal nativa por plantações de eucalipto, em diferentes sítios da Região Sudeste do Brasil. Revista Brasileira de Ciência do Solo, Viçosa, MG, v. 32, p. 1489-1499, 2008.

HATTENSCHWILER, S.; TIUNOV, A. V.; SCHEU, S. Biodiversity and litter decomposition in terrestrial ecosystems. Annual Review of Ecology Evolution and Systematics, Palo Alto, v. 36, n. 1, p. 191-218, 2005.

LOPES, M. I. M.; DOMINGOS, M.; VUONO, Y. S. Ciclagem de nutrientes minerais. In.: SYLVESTRE, L. S.; ROSA, M. M. T. Manual metodológico para estudos botânicos na Mata Atlântica. Seropédica: EDUR, 2002. p. 72-103.

LU, S. W.; LIU, C. P. Patterns of litterfall and nutrient return at different altitudes in evergreen hardwood forests of central Taiwan. Annals of Forest Science, Les Ulis, v. 69, n. 8, p. 877-886, 2012.

NOVRIYANTI, E.; WATANABEB, M.; KITAOC, M.; UTSUGIC, H.; UEMURAC, A.; KOIKEB, T. High nitrogen and elevated CO2 effects on the growth, defense and photosynthetic performance of two eucalypt species. Environmental Pollution, Barking, v. 170, p. 124-130, 2012.

OLSON, J. S. Energy storage and the balance of producers and decomposers in ecological systems. Ecology, v. 44, n. 2, p. 322$331,1963$.

RIBEIRO, M. A. V.; NOVAIS, R. F.; FAQUIN, V.; FERREIRA, M. M.; FURTINI NETO, A. E.; LIMA, J. M.; VILLANI, E. M. A. Resposta da soja e do eucalipto ao aumento da densidade do solo e a doses de fósforo. Revista Brasileira de Ciência do Solo, Viçosa, MG, v. 34, n. 4, p. 1157-1164, 2010. 
SANTANA, R. C.; BARROS, N. F.; NOVAIS, R. F.; LEITE, H. G.; COMERFORD, N. B. Alocação de nutrientes em plantios de eucalipto no Brasil. Revista Brasileira de Ciência do Solo, Viçosa, MG, v. 32, p. 2723-2733, 2008. Separata.

SEIN, C. C.; MITLÖHNER, R. Eucalyptus urophylla S.T. Blake: ecology and silviculture in Vietnam. Bogor Barat: CIFOR, 2011.

SILVA, P. H. M.; POGGIANI, F.; LACLAU, J. P. Applying sewage sludge to Eucalyptus grandis plantations: effects on biomass production and nutrient cycling through litterfall. Applied and Environmental Soil Science, New York, v. 2011, p. 1-11, 2011.

TANG, G.; LI, K.; ZHANG, C.; GAO, C.; LI, B. Accelerated nutrient cycling via leaf litter, and not root interaction, increases growth of Eucalyptus in mixed-species plantations with Leucaena Forest Ecology and Management, Amsterdam, v. 310, p. 45-53, 2013.

TEDESCO, J.; GIANELlO, C.; BISSANI, C. A.; BOHNEN, H.; VOLKWEISS, S. J. Análises de solo, planta e outros materiais. 2. ed. rev. e ampl. Porto Alegre: Departamento de Solos, UFRGS, 1995. $174 \mathrm{p}$.
TRAP, J.; BUREAU, F.; AKPA-VINCESLAS, M.; CHEVALIER, R.; AUBERT, M. Changes in soil $\mathrm{n}$ mineralization and nitrification pathways along a mixed forest chronosequence. Forest Ecology Management, Amsterdam, v. 258, p. 1284-1293, 2009.

TRAP, J.; LAVAL, K.; AKPA-VINCESLAS, M.; GANGNEUX, C.;DECAËNS, T.; AUBERT, M. Humus macro-morphology and soil microbial community changes along a 130- yr-old fagus sylvatica chronosequence. Soil Biology and Biochemistry, Elmsford, p. $1553-1562,2011$

ZHANG, D.; HUI, D.; LUO, Y.; ZHOU, G. L. Rates of litter decomposition in terrestrial ecosystems: global patterns and controlling factors. Journal of Plant Ecology, Oxford, v. 1, n. 2, p. 85-93, 2008. 